\title{
Factors Influencing the Effectiveness of Operational Information Sharing within Supply Chain Channels in Malaysia
}

\author{
Suhaiza Zailani \\ School of Management, Universiti Sains Malaysia, \\ 18000, Penang, Malaysia \\ Email: shmz@usm.my \\ R. Premkumar \\ Faculty of Business and Management \\ AIMST University, Jalan Bedong - Semeling, \\ 08100, Kedah, Malaysia \\ Email: dr_prem@AIMST.EDU.MY \\ Yudi Fernando \\ School of Management, Universiti Sains Malaysia, \\ 18000, Penang, Malaysia \\ Email: yudi_fernando@gmail.com
}

\begin{abstract}
The literature on supply chain and information has grown consistently over the past few years. This scenario reflects that that academics and practitioners have realized that in order for firms to become flexible, adaptable and efficient, they must focus their resources on managing the information throughout the supply chain channel. On the other hand, the competitive global marketplace requires firms to be flexible, for example they need to be able to share the information so that they can deliver materials with rapid cycle, or driving towards operational excellence. Although information sharing among trading partners is consistently mentioned as a key requirement of effectiveness supply chain management, research on information sharing is scarce particularly in Malaysian cases. This lack of research provides little guidance and support for those managers interested in improving their information sharing with the suppliers and customers. The main aim of this paper is to identify what are the factors influencing the effectiveness of operational information sharing. Questionnaires were sent to supply chain managers at E\&E firms in several industries in Malaysia. Five independent variables namely, information quality, IT commitment, SCM commitment, organizational size and trust were significantly related to operational information sharing. This finding indicates that it is extremely important to consider the quality of the information and the ability of the recipients to utilize the information based on differences in technologies being used, apart from their commitment on SCM, size of their organizations and trust among the partners. With the critical role that operational information plays in increasing the collaboration among supply chain partners, these factors are believed can facilitate the effectiveness of operational information sharing by supporting the practitioners to build capabilities to compete globally.
\end{abstract}

Keywords: Information sharing, Supply-chain management, Malaysia 


\section{Introduction}

A considerable amount of research has been undertaken towards supply chain management and now is well established in the literature. Thus, there is a range of literature on this subject ranging from integration, coordination, collaboration, and networking and to partnering (Lee, 2003). This shows that supply chain management has become a universal issue, and generated a great deal of discussion between the international academic and business communities all around the world. Importantly, supply chain has gained its importance due to its ability to reduce costs and increasing responsiveness in the chain ( $\mathrm{Li}$ et al., 2006). Concerning supply chain, many researchers have given many definitions on supply chain. Among the popular one would be by Lee (2001), which stressed that the supply chain encompasses all organizations and activities associated with the flow and transformation of goods from the raw materials stage, through to the end user, as well as the associated information flows. In other words, supply chain is the integration of key business processes from end user through original suppliers to add value and services to customer and stakeholders.

The definition of supply chain management (SCM) that could be also stated here would be by Handfield and Nichols (2002) that SCM is the integration of activities, through improved supply chain relationship to achieve sustainable advantage. SCM is also the management of supply chain organizations through cooperative organizational relationships, effective business processes, and high levels of information sharing to create highperforming value systems that provide member organizations a sustainable competitive advantage. It is widely accepted in the literature that SCM is important for material and information flows relating to the transformation of the materials into value added products, and the delivery of the finished products through appropriate channels to customers and markets to maximize customer value and satisfaction.

Realizing the importance of the supply chain as a universal issue, the Malaysian government has expanded the effort to prepare local industries to compete globally by automating their supply chain management processes (Yong, 2002).
As businesses begin competing globally, supply chain has become a primary focus which reflected the management of money, material gain and information throughout the supply pipeline. In an effort to increase effectiveness and efficiency of supply chain performance, many firms in Malaysia are now trying to coordinate entire supply chains. Recently, research on supply chain management has focused on a debate regarding the need for closer relationship between customer, supplier and other relevant parties in search for competitive advantage. However, the importance of supply chain management is that the sharing of information among firms in a supply chain. This is consistent with Brewer and Spehs' (2000) statement, in which, they claimed that sharing of information can reduce total supply chain costs and enhance value delivered to the customer, which can lead to sustainable competitive advantage for the firm.

Furthermore, the international literature consistently mentions the importance of sharing of information and how the development of strong relationships among supply chain partners, and what are the sophisticated information technologies that can help to expedite the information to be shared among partners (Derocher \& Kilpatrick, 2000; Mentzer et al., 2001). Walton and Miller (1995) and Moakley and Young, (1997), have identified adoption characteristics for a variety of technologies in relations to the effectiveness supply chain operations. While there have been numerous researches linking technology to supply chain performance (Gustin et al., 1995), little research has been conducted that has examined determinant factors for effectiveness information sharing in supply chains. This lack of research is troubling because information sharing is a key factor in effectiveness SCM (Evans \& Wurster, 1997). More specifically, the determinant factors of operational information sharing within supply chain settings have not been examined, leaving supply chain managers with little guidance about how to increase information sharing with other firms. The main goal of this paper is to identify potential determinant factors of operational information sharing. Therefore, research question of this paper is: "What are the determinant factors for the effectiveness of operational information sharing among companies?" The study was conducted in Malaysia. Due to the trend of globalization, the Malaysian 
government has delivered several policies to make Malaysia a global supply chain center. Many companies in Malaysia begin to pay more attention to operational information sharing due to global supply chain policies.

\section{Literature Review}

\subsection{Supply Chain Management (SCM)}

SCM focuses on how firms utilize their suppliers' processes, technology and capability to enhance competitive advantage. It is a management philosophy that extends traditional intra enterprise activities by bringing trading partners together with common goal of optimization and efficiency (Tan \& Handfield, 1998). SCM often requires the integration of inter and intra organizational relationships and coordination of different types of flows within the entire supply chain structure. However, a steady flow of information within an organization requires the development of an internal network and this applies to both the firm's partners and the supply chain partners. Information flow significantly influences material flow behaviour. Traditionally, companies have operated in environments characterised by inadequate information (Patnayakuni et al., 2006). The placing of periodic orders has been the primary informationsharing mechanism. Supply chain choices, for example production and inventory decisions, have been made based on local information at the site of activity. This has led to operational inefficiencies in the form of excess inventories, increased operational costs and additional coordination costs (Li \& Wang, 2007). As early as 1991, Perry noted that one of the most important implications for supply chain strategy in the coming decades is the growing importance of information in supply chain system design and operations. "Today information is a resource that is not only becoming more productive than in the past but also relatively less expensive when compared to alternative resources (such as people, material, equipment, and facilities). To a great extent, innovations in the design and management of today's forward-looking supply chain systems involve the more intensive use of information to achieve better control and visibility, resulting in lower supply chain costs and better customer service", (Perry 1991).

\subsubsection{Types of Information}

As noted in the paper by Li et al., (2005), information flow can be categorized according to operational areas such as inventory, sales, demand forecasting, order state and production plan (Lee \& Whang, 2000). Also noted in the paper by Koh et al., (2006), managing supply chain includes activities such as material sourcing, production scheduling and physical distribution system, but all these are supported by information flow which is necessary (Bovet \& Martha, 2003). Information flows from different directions in the supply chain. For example, based on explanation by Li et al., (2005), inventory and production plan information flows two-way between the downstream and upstream partners in the supply chain. Sales and demand forecasting information flows from downstream suppliers to their upstream partners. On the other hand, order state information flows from upstream to downstream partners. According to Chin et al., (2004), due to the advance of system-wide information and communication technologies, supply chain partners are able to share rich information to lower costs. Various software tools and techniques were used to enable speedy information flow to improve the efficiency and effectiveness of supply chain management.

Chin et al. (2004), suggested that effective information flow leads to a more trusting environment and commitment bring partners to work together to solve problems. As explained by Skjoett-Larsen et al., (2003), there was a high degree of information exchange in the business world at the end of the 1980s and 1990s which would lead to significant cost reductions. According to Rao Tummala et al., (2006), by allowing information to flow seamlessly, organizations are able to communicate more accurately and effectively about their abilities to meet costs, deadlines and logistics, which enable greater opportunity to manage the flow of materials and lower inventory levels across the supply chain. According to Mason and Towill (1997), the types of information sharing will vary, but generally there are three classes of information that managers will have to note e.g. planning information, control information and operational information (further discussed in the following sub sections). This paper, however, presents a study only on the operational information. In view of the 
importance of information flow as viewed by researchers, this serves as a basis for this paper to investigate the effectiveness of the operational information.

\subsubsection{Planning Information}

This type of information relates to the tasks of formulating objectives, determining the amounts and kinds of resources necessary to attain the objectives, and the policies that govern their use (Mason \& Towill, 1997). Much of this information will come from external sources and will relate to such factors as the present and predicted situation in the operational area, availability of resources (material, financial and human), and the political environment. This information forms the input to the non-programmed types of decisions made at each level in the organization. Some examples of such information would be build plan forecasts, material demands, and customer order numbers. This information would be very useful for channel partners and the key would be to make it available in a timely manner.

\subsubsection{Control Information}

This information aids managers to make decisions which are consistent with the achievement of organizational objectives and to see how efficiently resources are being used (Mason \& Towill, 1997). It enables managers to determine if "actual results" are meeting the "plan of records" (objectives). It relies heavily on internal sources of information and involves such problems as sourcing resources and measuring the performances of both the focal firm and its suppliers. The nature of problems faced at this level may result in either programmed or nonprogrammed types of decisions. Getting this information shared within the firm and to relatedextended enterprises would benefit the channel members to make the necessary alignment or correction before the actual performance is due for measurement.

\subsubsection{Operational Information}

This information relates to the day-to-day activities of the organization. Operational data in manufacturing are usually required in three broad categories: people, material and tools capacity, and the daily operations status. It includes routine and necessary types of information for decision making in operations which includes, inbound shipment arrival, raw material inventory status, WIP analysis and the finished goods schedule (Mason \& Towill, 1997). Most of the information is generated internally, and since it usually relates to specific tasks of the channel partners, it is often allowed to flow upstream and downstream in a chain. Field-level managers are the primary users of this information and they will have to ensure that the information is not static at any point but should be allowed to flow. However from the strategic perspective, managers will have to identify intelligence information which includes data on the various elements of the organization's operating environment such as victims, other agencies, relief suppliers, and the local government. It also includes information on trends and patterns, as well as developments in the social and cultural environment in which the organization operates. This type of information has long-term significance to the organization and aids; in longrange, strategic planning. Such information should be restricted from the general flow, in other words, managers should control its access to the extended enterprises beyond the firm to exercise control and protect the firm from being vulnerable.

\subsection{Information Sharing in Supply Chains}

Information sharing has been shown to be one of the keys to successful supply chains (Whipple et al. 2002). There are various definitions of information sharing. Lee and Whang (2000) defined it as the transfer of information regarding inventory levels and position, sales data and forecasts, order status, production and delivery schedules and capacity, and performance metrics. Sanders and Premus (2005) view information sharing as "providing firms with forward visibility, improved production planning, inventory management, and distribution" in their study of IT capabilities, collaboration, and firm performance. Information sharing includes, but is not limited to, the transfer of information in shipment tracing, billing transactions, and complaint resolutions.

On the other hand, Stevenson and Spring (2007) stated that accurate and real-time information flow in the supply chain is considered as important as material flow by most organizations. Hull (2002) stated that "an information-enriched supply chain would have a single customer entity connected to 
every scheduling process, showing order information flowing to all links. For a non-enriched supply chain, the customer entity might connect only to the final scheduling link, leaving the remainder of the supply chain hidden from the customer". On the other hand, information sharing is an important element that reflects cooperation in supply chain management. According to Simatupang and Sridharan (2005), information sharing is "the ability to see private data in a partner's systems and monitor the progress of products as they pass through each process in the supply chain. This activity includes monitoring (data capturing), processing, and dissemination of customer data, end-to-end inventory status and locations, order status, costs-related data, and performance status".

The benefits of information sharing on supply chain performance have been dealt with in several studies. Shared information can improve decisions with regard to the quantity in a supplier's orders and the allocation of the supplier's inventory across retailers (Lee \& Whang, 2000; Lee et al., 2000). There has been various research activities carried out that address the business potential of sharing data across the supply. Huang et al, (2006) studied the importance of data in supply chain. Li and Lin (2006) study the impact of environmental uncertainty, intraorganisational facilitators, and interorganisational relationships on information sharing and information quality in supply chain management. Data were collected in a field survey from 196 companies. The researchers find significant support for the hypothesis that information sharing is positively impacted by top management support, trust, and shared vision between supply chain partners. Supplier uncertainty had a negative effect on information sharing and also on information quality. Customer uncertainty, supplier uncertainty and technology uncertainty lowered the level of information quality and information sharing. However, according to Huang et al (2006), the level of information quality and information sharing may be influenced negatively by the length of a supply chain. Information suffers from delay and distortion as it travels along the supply chain, the shorter the supply chain, the less chance it will get distorted.

Following the above discussions, Derocher and Kilpatrick (2000), SCM theory has clearly established that information sharing is a key component of effectiveness supply chains. For example, Gustin et al. (1995) found that firms with highly integrated supply chain departments reported higher amounts of available information and stronger performance from their information systems. In addition, Rogers et al (1996) examined the linkage between technology usage and warehousing performance, and firms that were high users of warehousing information technology reported higher levels of warehousing performance in some areas. Ellinger (1997) then discovered that the degree of marketing and supply chain integration was found to have a positive relationship with supply chain service and firm performance.

\subsection{Factors Influencing the Effectiveness of Operational Information Sharing}

Operational information is defined as "short-term quantitative information about daily logistics/sales activities or status information on orders and inventory levels" (Moberg et al., 2003). It concerns the actual material flow between the supply chain partners and covers functionalities that support the operational aspects of the supply chain, such as inventory management, warehousing, etc. (Muzumdar \& Narayan, 2001). In other research, the amount of operational information sharing between manufacturers and third party providers of international supply chain services positively affected customer perceptions of responsiveness and supply chain performance (Stank et al., 1996a). Stank et al. (1996b) has identified the positive effect of operational information sharing on supplier performance has also been examined. Recently, Ellinger et al. (2000) examined the importance of interdepartmental integration to supply chain performance.

Operational information sharing is treated as one component of the overall integration among firms or departments. However, lack of operational information with regards to demand visibility has been identified as an important challenge for supply chain management (Chen, 1998 \& Lee, 2002). These were again stressed by Cachon and Fisher, (2000), who claimed that operational information e.g. demand is absolutely important for firms to make decision on the building plan, the right number of units to be produced. The more accurate the operational information the better the avoidance of bullwhip effect along the chain. A bullwhip effect is 
defined as increasing variability in order sizes as one move upstream in the supply chain (Lee et al, 1997). The effect of bullwhip between supply chain players can affect supply chain performance. This is supported by Lee et al (2002). He claimed that if operational information on inventory level and velocity are not easily available, it will lead to inefficient capacity utilization, poor product availability, and high stock levels.

\subsection{Underlying Theories/Model}

Porter (1985) defined value chain analysis as "describing the activities that an organization performs within and around an organization and relates them to the organization competitive strength". Hence, value chain analysis evaluates the value that each particular activity adds to the products or services. In the model that Porter developed, he distinguished two different types of activities, namely the primary activities and support activities. Primary activities are directly related to the manufacturing and delivery of products and services, whereas the support activities play the role of helping the primary activities to improve the effectiveness and efficiency.

\section{Theoretical Framework}

The theoretical framework is deduced from Porter Value Chain Model and previous researches and literatures. Based on the above discussions, the research framework is developed to investigate the relationships between supply chain variables and operational information sharing (see Figure 1). Three variables were identified as potential factors of effectiveness operational information sharing: information characteristics, organizational characteristics and environmental characteristics or the strength of the relationship between sharing partners. These variables are supported by the literature reviews. For example, Kwon and Zmud (1987) classified variables affecting information sharing into individual, task-related, innovationrelated, organizational, and environmental characteristics. Tornatzky and Fleischer (1990) suggested that the extent of information sharing is affected by technological, organizational, and environmental context. Peterson et al. (2005) indicated that information sharing affected by organizational size, structure, and performance, supply chain strategy, transaction climate, supply chain member pressure, and environmental uncertainty. This paper, however, only investigates the influence of information, organizational, and environmental characteristics on operational information sharing. While information sharing has been identified and defined as operational in the literature (Gustin et al., 1995). Operational information sharing typically encompasses shortterm, quantitative information about daily supply chain/sales activities or status information on orders and inventory levels. It is primarily used to reduce order cycle times and inventory levels and to improve customer service. Thus, the theoretical framework that is developed for this study is a follows:

Figure 1: Research framework

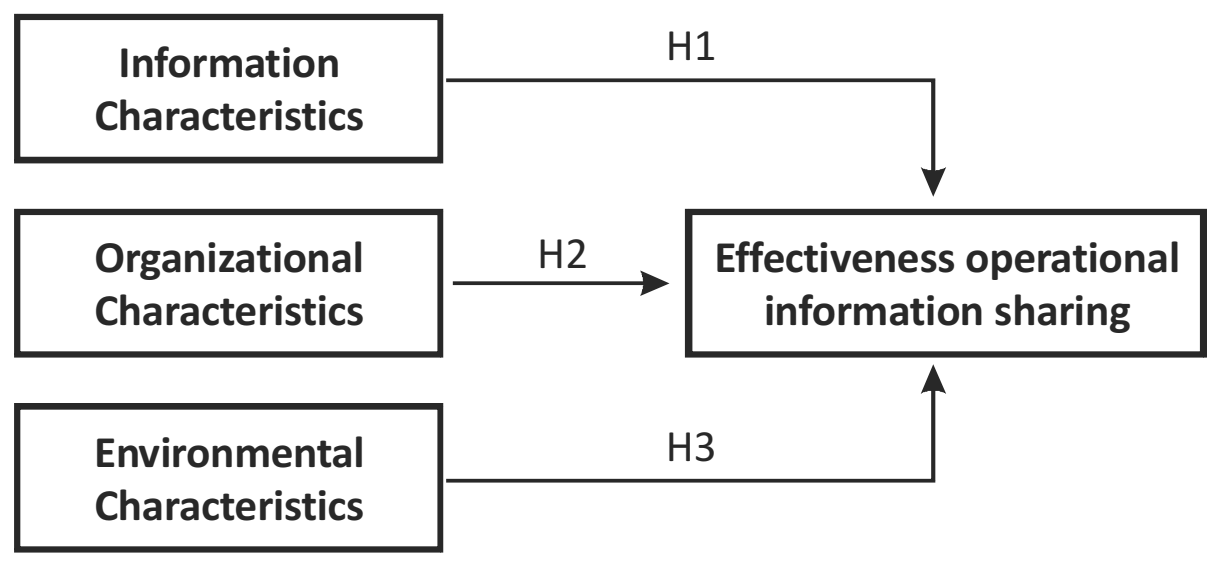




\subsection{Information Characteristics}

nformation quality is a multidimensional concept encompassing critical relationships among multiple attributes, such as timeliness, accuracy, and relevancy (Naumann \& Rolker, 2000). Together, these attributes contribute to the validity of the information. Good information quality is the cornerstone for decision making. The typical triggers for poor information quality are commonplace business challenges such as incomplete records, delays, failure to update record information, dataentry mistakes, or improper releases of information. According to Moberg et al (2002), if the perceived value of the information decreases because of poor information quality, less information will be sharing. Based on the above discussions, the following hypothesis is proposed:

H1. There is a positive relationship between information quality and effectiveness of operational information sharing.

\subsection{Organizational Characteristics}

The resource-based view (RBV) suggests that a firm develops organizational resources that enhance the organization's performance. The firm's resources include tangible and intangible factors such as physical assets, human capital, and intra-/ interorganizational routines and procedures. "If efforts are focused on developing the 'right' capabilities, performance will be enhanced", claimed Seidmann and Sundararajan (1998). The successful of sharing information is affected by certain features of organizations such as structures, climates, and cultures of organizations (Kimberly \& Evanisko, 1981). In conjunction with IT, it is believed that the information technology such as the intranet, extranet, Internet, WWW and EDI facilitate the realtime or timeliness of information in a chain (Zailani \& Rajagopal, 2006). Lee et al (2001) study of information technology managers in Korea showed that organizational characteristics moderated the association between information sharing and IT outsourcing success. Lee et al., (2001) operationalization of organizational capability included the IT commitment. Therefore, it is critical that top levels of management demonstrate commitment to the latest development in IT. Moberg et al (2002) have suggested that support by top management is necessary to generate support throughout the company, which should lead to increased information sharing. Based on the above discussions, the following hypothesis is proposed:

$\mathrm{H} 2 \mathrm{a}$ There is a positive relationship between top management commitment to IT and effectiveness of operational information sharing.

Balaporia (2002) argues that larger firms are more committed to share the information because they have more resources and they are more visible to the suppliers or customers. This is due to the reason that those larger organizations tend to be more diverse and complex, and the increased availability of resources can lead to more risk-taking by management because potential failure is less hazardous to the health of a large organization (Damanpour, 1987). This has been confirmed by previous research that found larger organizations adopt more innovations (Kim, 1980; Kimberly \& Evanisko, 1981). Based on the above discussions, the following hypothesis is proposed:

$\mathrm{H} 2 b$. There is a positive relationship between size of the organization and effectiveness of operational information sharing.

Management belief in and commitment to SCM principles should also be essential to information sharing. Higginson and Alam (1997) have identified top management commitment to SCM as a key component of effectiveness implementation. Based on the above discussions, the following hypothesis is proposed:

$\mathrm{H} 2 \mathrm{c}$ There is a positive relationship between top management commitment to SCM and effectiveness of operational information sharing.

\subsection{Environment Characteristics}

Trust is an important social process for developing cross-boundary information sharing among organizations and individuals. According to Moorman et al (1992), the level of trust among participating organizations is particularly relevant to information sharing efforts because it can 
alleviate conflicts and ease the way for collaboration in the form of risk taking, knowledge sharing, and decision making. A high level of trust can contribute to full participation in the project and knowledge sharing about complex business processes and practices. This is supported by many researchers such as Morgan and Hunt, (1994). They claimed that when the channel partners trust that members in the chain, they would invest heavily in information sharing. Moorman et al. (1993) defined trust as "the willingness to rely on a sharing partner in whom one has confidence." Trust should be a key factor in predicting information sharing if the supply chain members are reluctant to share information. Moberg et al (2002) suggested that the amount of information sharing between channel members should increase as the strength of the relationship increases; hence the relationships are stronger as trust increases. Based on the above discussions, the following hypothesis is proposed:

H3a. There is a positive relationship between trust and effectiveness of operational information sharing.

On top of trust, commitment is also one of the elements in the strong relationship. Moorman et al. (1992) define commitment to a relationship as "an enduring desire to maintain a valued relationship." Or in other words, firms that are committed to relationships with valued partners in the supply chain will work hard to maintain the relationship. In conjunction with this, Morgan and Hunt (1994) proposed that commitment was an essential part of relationship marketing and it is a crucial variable in strong relationships. Again, based on Moberg et al (2002), they argued that the increased of information sharing requires effort and an increase in resource allocations, firms are more likely to sharing information with those trading partners that demonstrate a long-term commitment to the relationship. Based on the above discussions, the following hypothesis is proposed:

$H 3 b$. There is a positive relationship between relationship commitment and effectiveness of operational information sharing.

\section{Methodology}

In most studies on supply chains, mail surveys were found to be the preferred method. There have been a number of surveys investigating supply chain management. For example, Fawcett and Magnan (2001), and Yu et al. (2002), conducted mail surveys to study supply chain alignment; benefits, barriers, and bridges. These studies were to establish databases on world-class supply chains and to collect necessary information about the factors contributing to effective supply chain. For this reason, therefore, a mail-survey was used in this research to shed some light on operational information sharing in the chains. This study involved manufacturing firms in Malaysia, therefore, firms that were listed in the 2004 FMM Directory are represented the population frame for the study. From these firms, it was decided to narrow the population by focusing on the electrical and electronics industry. Importantly, the electrical and electronics industry, characterized by rapid technological changes, is the major high technological area that forms the business battleground between Malaysia and other Asian countries led by Japan, Hong Kong, Taiwan and Singapore.

As suggested by Sekaran (2003), the analysis samples should be at least 10 times the number of variables in a study. Thus, 60 respondents are the minimum number of samples in this study, as there are a total of 6 variables. There are 672 electrical and electronics firms in Malaysia and specifically 584 MNC and SME's, the study decided to use MNC and SME population as the sample. A firm is used as the unit of analysis due to the aim of the study, which is to identify the determinants that affect the effectiveness of operational information sharing. The mail survey through a questionnaire was directed to the supply chain or purchasing managers of the electrical and electronics firms. These managers were chosen since they were deemed more likely to be heavily engaged in supply chain management, and therefore were more likely to be involved with information among partners. It is believed that this would maximize the validity of the research content.

The measured scales were submitted to factor analysis and information characteristic is factorized by "information quality". Although there are no 
Table 1: Measured Scales

Items
Operational Information Sharing
1. Sales
2. Order status
3. Production schedules
4. Inventory levels
5. Forecast demand
Information Quality
1. Timeliness
2. Accuracy
3. Consistency
4. Completeness

\footnotetext{
Information technology commitment

1. Awareness of EDI and Internet

2. Willing to implement

3. Continued usage
}

Supply chain management com
1. Awareness of SCM
2. Willing to implement
3. Continued usage
Trust
1. Retailer keeps promises
2. Retailer not always honest
3. Believable information
4. Genuinely concerned
5. Considers our welfare
6. Keeps our nest interest in mind
7. Trustworthy
8. Need to be cautions

\footnotetext{
Relationship commitment

1. Continue for a long time

2. Strengthen over time

3. Considerable effort and investment

4. Invested a lot of effort

5. Relationships is a partnerships
}

uniformed lists for the information quality dimensions, the study adopt one of the commonly identified information quality dimensions for the purpose of this research which are: - Accuracy, which occurs when the recorded value is in conformity with the actual value; Timeliness, which occurs when the recorded value is not out-of-date; Completeness, which occurs when all values for a certain variable are recorded; and Consistency, which occurs when the representation of the data values is the same in all cases (Ballou et al., 1987). These dimensions were used in this study as they are believed to work well in the supply chain environment. This is supported by Balaporia (2003) in his study in the context of supply chain. He claimed that the right data, with the right completeness, in the right context, with the right accuracy, in the right format, at the right time, at the right place and for the right purpose.

Organizational characteristics are factorized by "IT commitment", "SCM commitment" and "organizational size"; environmental characteristics are factorized by "trust" and "relationship commitment". These dimensions were adapted from Moberg et al (2002). The size of organizational was measured by using open question. For the rest of the scales, a 5-point Likert scale was used to measure managers' views on the extent of the determinants being practiced in the firm. The scale ranged from "very little" to "a great extent". On the other hand, the scale used to measure the effectiveness information sharing ranged from "highly disagree" to "strongly agree". As Lee and Whang (1988) indicate, the most common data shared between supply chain partners is inventory level, sales, demand forecast, order status, and production schedule. Operational information sharing typically encompasses short-term and quantitative information (see Table 1).

\section{Analysis}

The overall response rate of 137 replies to 584 requests represented a rate of 23.45 percent of which $8(1.36 \%)$ were unusable. Analysis of the 8 unusable responses reveals no systematic factor at work. The main reason of a company policy not to take part in surveys accounted for $25 \%$ of the 8 . A further $50 \%$ simply did not wish to respond although this was not specified as company policy. A total of $1 \%$ other reasons was given including time pressure, "quality manager is busy'. After eliminating the non-usable responses, 129 usable responses were received. In other words, a usable response rate of $22.08 \%$ is good for this type of survey given the complexity of the survey instrument. The response reflected industry interest in the subject matter. In this survey, however, 6 questionnaires were returned undelivered due to several reasons such as, the companies had gone away with no forwarding addresses or letters were unclaimed and insufficient 
address. Relative to similar survey-based research, a usable rate of $22 \%$ is indeed very healthy.

Of 129 companies that completed the questionnaire, only 19 respondents declined to give their personal details. The rate of identity disclosure in the survey was $82 \%$. The questionnaire was answered mostly by procurement managers themselves $(73 \%)$ or by assistant procurement manager $(6 \%)$ and only $4 \%$ by junior officers. All the respondents were either professionally qualified or had an extensive background in quality as evidenced by their degree in engineering or work experience of for more than 10 years. Since all respondents had extensive knowledge in supply chain management, the problem of survey completion without a sound understanding of the technical matter was avoided. The working experience for the respondents ranged from 2 to 25 years with an average of approximately 6 years. The respondents were aged from 24 to 63 years old with an average of approximately 39 years. Generally, the respondents had considerable years of working experience that enabled them to fully understand their companies and consequently, give reliable answers. $82 \%$ of the survey's respondents were men. The presence of a small number of female respondents in the survey was not surprising since key positions in companies are normally male dominated in Malaysia.

Table 2: Factor Loadings for Independent Variables - Rotated Component Matrix

\begin{tabular}{|c|c|c|c|c|c|}
\hline \multirow[b]{2}{*}{ INFORMATION QUALITY } & \multirow[b]{2}{*}{$I Q$} & \multicolumn{4}{|c|}{ Component } \\
\hline & & IT & SCM & Trust & Commitment \\
\hline Timeliness & $\underline{0.77}$ & 0.17 & 0.23 & 0.13 & 0.17 \\
\hline Accuracy & $\underline{0.79}$ & 0.26 & 0.26 & 0.11 & 0.14 \\
\hline Consistency & $\underline{0.86}$ & 0.19 & 0.17 & 0.12 & 0.22 \\
\hline Completeness & $\underline{0.83}$ & 0.28 & 0.12 & 0.17 & 0.09 \\
\hline \multicolumn{6}{|l|}{ IT COMMITMENT } \\
\hline Awareness of EDI and Internet & -0.01 & $\underline{0.82}$ & 0.28 & 0.14 & 0.11 \\
\hline Willing to implement & 0.30 & $\underline{0.63}$ & 0.11 & 0.20 & 0.24 \\
\hline Continued usage & 0.24 & $\underline{0.85}$ & -0.01 & -0.02 & -0.13 \\
\hline \multicolumn{6}{|l|}{ SCM COMMITMENT } \\
\hline Awareness of SCM & 0.30 & -0.08 & $\underline{0.64}$ & 0.22 & 0.18 \\
\hline Willing to implement & 0.18 & 0.24 & $\underline{0.61}$ & -0.13 & 0.27 \\
\hline Continued usage & 0.19 & 0.18 & $\underline{0.65}$ & 0.00 & 0.13 \\
\hline \multicolumn{6}{|l|}{ TRUST } \\
\hline Retailer keeps promises & 0.07 & 0.02 & 0.05 & $\underline{0.78}$ & 0.15 \\
\hline Retailer not always honest & 0.06 & 0.05 & -0.01 & $\underline{0.82}$ & 0.25 \\
\hline Believable information & 0.18 & 0.15 & 0.07 & $\underline{0.77}$ & -0.03 \\
\hline Genuinely concerned & 0.14 & 0.10 & 0.25 & $\underline{0.70}$ & 0.02 \\
\hline Considers our welfare & 0.18 & 0.05 & 0.10 & $\underline{0.74}$ & 0.07 \\
\hline Keeps our nest interest in mind & 0.25 & 0.20 & 0.13 & $\underline{0.75}$ & 0.24 \\
\hline Trustworthy & 0.20 & 0.13 & 0.11 & $\underline{0.77}$ & 0.11 \\
\hline Need to be cautions & 0.30 & 0.20 & 0.18 & $\underline{0.61}$ & 0.12 \\
\hline \multicolumn{6}{|l|}{ COMMITMENT } \\
\hline Continue for a long time & 0.21 & 0.15 & 0.11 & 0.08 & $\underline{0.85}$ \\
\hline Strengthen over time & 0.20 & 0.29 & 0.04 & 0.30 & $\underline{0.81}$ \\
\hline Considerable effort and investment & 0.23 & -0.03 & 0.13 & -0.04 & $\underline{0.83}$ \\
\hline Invested a lot of effort & 0.04 & 0.21 & -0.07 & 0.26 & $\underline{0.80}$ \\
\hline Relationships is a partnerships & 0.14 & 0.26 & 0.11 & 0.12 & $\underline{0.78}$ \\
\hline KMO Measure of Sampling Adequacy & \multicolumn{5}{|c|}{.85} \\
\hline Bartlett's Test of Sphericity $-\chi^{2}$ (d.f) & \multicolumn{5}{|c|}{$1691.69(378)$} \\
\hline
\end{tabular}


Table 3: Factor Loadings for Dependent Variable

\begin{tabular}{|l|lc|}
\hline Code & Effectiveness of Operational Information Sharing & Loading \\
\hline DS1 & Inventory Levels & $\underline{\mathbf{0 . 8 2}}$ \\
DS2 & Order Status & $\underline{\mathbf{0 . 7 6}}$ \\
DS3 & Production Schedules & $\underline{\mathbf{0 . 8 0}}$ \\
DS4 & Advanced Shipping Notice & $\underline{\mathbf{0 . 8 5}}$ \\
\hline KM0 Measure of Sampling Adequacy & .82 \\
Bartlett's Test of Sphericity - $\chi^{2}$ (d.f) & $171.10(10)$ \\
\hline
\end{tabular}

\subsection{Factor Analysis}

In this study, two factor analyses (see Table 2 and 3) were run to verify the postulated dimensionality of the independent and dependent variables respectively. The analyses provided a clean factor structure with items loading on the appropriate factors. The cut off point of factors loadings for retention is .50 (Hair et al., 2005). All items showed high loadings that are more than .50 and thus, no items were deleted due to low or incorrect loading.

\subsection{Reliability Analysis}

Factor analysis and coefficient alphas were used to assess the validity and reliability of the multiple-item measures. Nunnally (1978) has previously indicated that coefficient alphas as low as 0.60 are acceptable in social science research. The smallest value of Cronbach's \pm for this study is 0.6742 . This implies that the sampling results are reliable. After passing the validation and reliability procedure, retained items were then aggregated into a collective sum. The alpha coefficients for all dimensions are reported in the following factor analyses tables (Table 4).

\subsection{Validity and Reliability of Measures}

The mean was applied as a measure of central tendency, which indicated that all variables were above their midpoint level as indicated in Table 5 . Out of the five independent variables, information quality was the highest in rating $(\mathrm{M}=3.71)$, while commitment was the lowest $(\mathrm{M}=2.74)$. Dependent

Table 4: Result of the Reliability Test

\begin{tabular}{lccc}
\hline \multicolumn{1}{c}{ Variable } & No of Item & Item Dropped & Cronbach's Alpha \\
\hline Information Quality & 4 & - & .8101 \\
IT Commitment & 3 & - & .8622 \\
SCM Commitment & 3 & - & .9254 \\
Trust & 8 & - & .9622 \\
Relationships Commitment & 5 & - & .6742 \\
Effectiveness Operational & 4 & - & .8509 \\
Information Sharing & & & \\
\hline
\end{tabular}

Table 5: Characteristics of the Variables

\begin{tabular}{lcccc}
\hline \multicolumn{1}{c}{ Variables } & Minimum & Maximum & Mean & Std. Deviation \\
\hline Information quality & 2.44 & 5.00 & 3.72 & .71 \\
IT commitment & 2.04 & 5.00 & 3.52 & .88 \\
SCM commitment & 1.74 & 5.00 & 3.37 & .77 \\
Trust & 1.50 & 5.00 & 3.25 & .66 \\
Commitment & 0.64 & 5.00 & 2.74 & .74 \\
Effectiveness Operational information sharing & 1.00 & 5.00 & 3.00 & .74 \\
\hline
\end{tabular}


Table 6: Correlation between Variables

\begin{tabular}{|c|c|c|c|c|c|c|c|}
\hline Variable & 1 & 2 & 3 & 4 & 5 & 6 & 7 \\
\hline Information quality & .90 & & & & & & \\
\hline Organizational size & $.72^{\star *}$ & .95 & & & & & \\
\hline IT commitment & $.56^{\star \star}$ & $.39^{\star \star}$ & .89 & & & & \\
\hline Supply chain commitment & $.42^{\star *}$ & $.45^{\star \star}$ & $.39^{\star *}$ & .81 & & & \\
\hline Trust & $.60^{\star \star}$ & $.54^{\star *}$ & $.52^{\star *}$ & $.43^{\star \star}$ & .78 & & \\
\hline Commitment & $.68^{\star *}$ & $.68^{\star \star}$ & $.48^{\star \star}$ & $.52^{\star \star}$ & $.63^{\star *}$ & .91 & \\
\hline Effectiveness operational information sharing & $.59^{* \star}$ & $.87^{\star \star}$ & $.86^{\star \star}$ & $.78^{\star \star}$ & $.58^{* *}$ & $.68^{\star \star}$ & .89 \\
\hline
\end{tabular}

${ }^{\star \star}$ Correlation is significant at the 0.01 level (1-tailed).

variables' mean values were also in the range of 3 in the 5-point Likert scale. In other words, all variables exhibited a standard deviation of less than 1 .

\subsection{Predictive and Discriminant Validity}

All independent variables were found to be significantly correlated with the dependent variable of effectiveness operational information sharing. Both Information quality and Organizational size have similar and high correlation values $(r=.59$, $\mathrm{p}<.01)$ as independent variables with effectiveness information sharing. This is followed by IT commitment $(\mathrm{r}=.52, \mathrm{p}<.01)$ and SCM commitment $(\mathrm{r}=.48, \mathrm{p}<.01)$. Table 6 presents the results of this test.

Table 7: Multiple Regression

\begin{tabular}{|l|c|}
\hline \multicolumn{1}{|c|}{ Variables } & Standard Coefficient (Beta) \\
\hline & Effectiveness Operational Information Sharing \\
Information quality & 0.071 \\
IT commitment & 0.274 \\
Supply Chain commitment & 0.088 \\
Organizational size & 0.182 \\
Trust & 0.292 \\
Commitment relationships & 0.004 \\
R $^{2}$ & 0.623 \\
Adjusted R & 0.598 \\
F & 25.569 \\
Sig F & 0.000 \\
Durbin Watson & 2.028 \\
\hline
\end{tabular}

${ }^{*} p<0.01$

\subsection{Hypothesis Testing}

The method of regression analysis was used to examine the influence of determinant factors on effectiveness operational information sharing.

The $\mathrm{R}$ square value indicated that $62.3 \%$ of variance in Effectiveness Operational Information Sharing can be explained by the 6 variables $\left(R^{2}=0.623\right.$; $\mathrm{F}=25.569 ; \mathrm{p}<0.05)$. The regression result in Table 7 shows that Information quality, IT commitment, Supply Chain commitment, Organizational size and Trust are significant determinants for effectiveness operational information sharing except Commitment relationships $(\beta=0.004 ; p<0.05)$ is not significant to effectiveness operational information sharing. In short, hypotheses $\mathrm{H} 1, \mathrm{H} 2 \mathrm{a}, \mathrm{H} 2 \mathrm{~b}, 2 \mathrm{c}$ and $\mathrm{H} 3 \mathrm{a}$ is supported. Table 7 shows that the highest standard coefficients are trust variable which is 0.292. Furthermore, the Durbin-Watson value is 2.028 which proved that there is no autocorrelation problem because it is in range 1.50 to 2.50 . In this test, it shows that there is $62.3 \%$ variations $\left(R^{2}\right)$ can be explained by all the independent variables while there are $37.7 \%$ of the variations cannot be explained by all the independent variables. Standard Coefficients (Beta) for trust is $0.292(p<0.01)$ gives the most impact to the effectiveness operational information sharing in the companies. Besides, the Standard Coefficients for Commitment relationships has the lowest impact to the effectiveness operational information sharing which is $0.004(p<0.01)$. Therefore, hypothesis H1f is rejected while other hypothesis is accepted. The significant value $F=0.000$ which is $p<0.01$. Thus, the null hypothesis is rejected and alternative hypotheses are accepted and this model is authentic. As a conclusion the tests conducted can be summarized as below: 
Table 8: Summary of Analysis

\begin{tabular}{|c|c|c|c|}
\hline & Hypotheses & Standard Coefficient (Beta) & Result \\
\hline & $\begin{array}{l}\text { There is a positive relationship between determinant factors and } \\
\text { the effectiveness operational information sharing. }\end{array}$ & 0.531 & Accept \\
\hline H1a & $\begin{array}{l}\text { There is a positive relationship between information quality and } \\
\text { the effectiveness operational information sharing. }\end{array}$ & 0.071 & Accept \\
\hline $\mathrm{H} 2 \mathrm{a}$ & $\begin{array}{l}\text { There is a positive relationship between IT commitment and } \\
\text { the effectiveness operational information sharing. }\end{array}$ & 0.274 & Accept \\
\hline $\mathrm{H} 2 \mathrm{~b}$ & $\begin{array}{l}\text { There is a positive relationship between SCM commitment and } \\
\text { the effectiveness operational information sharing. }\end{array}$ & 0.088 & Accept \\
\hline $\mathrm{H} 2 \mathrm{C}$ & $\begin{array}{l}\text { There is a positive relationship between organizational size and } \\
\text { the effectiveness operational information sharing. }\end{array}$ & 0.182 & Accept \\
\hline H3a & $\begin{array}{l}\text { There is a positive relationship between trust and the effectiveness } \\
\text { operational information sharing. }\end{array}$ & 0.292 & Accept \\
\hline $\mathrm{H} 3 \mathrm{~b}$ & $\begin{array}{l}\text { There is a positive relationship between relations commitment and } \\
\text { the effectiveness operational information sharing. }\end{array}$ & 0.004 & Reject \\
\hline
\end{tabular}

\section{Concluding Remarks}

The major goal of this paper was to identify variables that were significantly related to operational information sharing so managers could develop strategies for increasing interorganizational information sharing. The results indicate that information quality IT commitment, Supply Chain commitment, Organizational size and Trust are significantly related to operational information sharing. These findings are important because they reinforce the importance of building strong relationships with trading partners and making an effort to improve the accuracy, timeliness, and formatting of information that is sharing within the supply chain. Based on the apparent importance of the six independent variables in the supply chain literature, it was somewhat surprising, and troubling, that commitment relationship is not significantly related to operational information sharing. With such strong literature support, the non-significant results may be explained by the methodology limitations in the study or they could be an indication that there are serious concerns about the validity of current SCM theory. The effectiveness of operational information sharing is a critical component of SCM because supply chain managers need more guidance from the literature about methods they can use to facilitate and increase the effectiveness of operational information sharing; discussing the method flaws of the research and the implications of the non-significant results is valuable.

\subsection{Limitations of the research}

One of the limitations of the study is the absence of other variables that may be antecedents of operational information sharing. While this study examined six potential antecedents of operational information sharing, there are other variables that should be considered in future studies, such as organizational culture, uncertainty avoidance, and risk-taking propensity. More empirical research that identifies the antecedents of information sharing and further explores the role of operational information sharing in supply chain settings is needed. With the critical role that operational information sharing plays in increasing the collaboration among supply chain partners, the identification of antecedents that will facilitate sharing should prove invaluable to supply chain managers as they implement SCM initiatives.

\section{References}

Bovet, D. and Martha, J. (2003). Value nets: reinventing the rusty supply chain for competitive advantage. Strategy $\mathcal{E}$ Leadership, 20 (4), pp. 21-26.

Balaporia, Z (2002), Impact of Information Quality in Supply Chain Management, Seventh International Conference on Information Quality (IQ 2002) edited by Craig Fisher and Davidson, pg 65-68,

Brewer, P.C., Speh, T.W. (2000). Using the balanced scorecard to measure supply chain performance, Journal of Business Supply chain, 21 (1), pp.75-94. 
Chin, K., Tummala, V., Leung, J., \& Tang, X. (2004). A Study on Supply Chain Management Practices: The Hong Kong Manufacturing Perspective. International Journal of Physical Distribution and Logistics Management, 34(6), 505-524.

Damanpour, F. (1987). The adoption of technological, administrative, and ancillary innovations: impact of organizational factors, Journal of Management, 13(4), pp.675-88.

Derocher, R.P., Kilpatrick, J. (2000). Six supply chain lessons for the new millennium, Supply Chain Management Review, 3 (4), pp.34-41.

Ellinger, A.E. (1997). “The Relationship between Marketing/ Logistics Interdepartmental Integration and Performance in U.S. Manufacturing Firms: An Empirical Study," Journal of Business Logistics, Vol. 21, No. 1, pp. 1-23.

Evans, P.B., Wurster, T.S. (1997). Strategy and the new economics of information, Harvard Business Review, 75(2), pp.71-82.

Gustin, C.M., Daugherty, P.J., Stank, T.P. (1995). The effects of information availability on supply chain integration, Journal of Business Supply chain, 16(1), pp.1-21.

Hair, J.F., Anderson, R.E., Tatham, R.L., Black, W.C. (1992), Multivariate Data Analysis, Macmillan Publishing, New York, NY,

Handfield, R.B. \& Nichols, E.L. (2002). Introduction to Supply Chain Management. New Jersey, USA: Prentice Hall.

Higginson, J.K., Alam, A. (1997). Supply chain management techniques in medium-to-small manufacturing firms, The International Journal of Supply chain Management, 8(2), pp.19-31.

Huang, G. Q., Lau, J. S. K., \& Mak, K. L. (2003). The impact of sharing production information on supply chain dynamics: a review of the literature. International journal of Production Research, 41(7), 1483-1517

Hull, B. (2002). A Structure for supply-chain information flows and its application to the Alaskan crude oil supply chain, Logistics Information Management 15(1): pp. 8-23.

Kim, L. (1980). Organizational innovation and structure, Journal of Business Research, 8 (2), pp.225-45.

Kimberly, J. and Evanisko, M. (1981). Organizational Innovation: The Influence of Individual, Organisational, and Contextual Factors on Hospital Adoption of Technological and Administrative Innovations, Academy of Management Journal 24(4): pp. 689-713.

Koh, S. C. L., Saad, S., \& Arunachalam, S. (2006). Competing in the 21st century supply chain through supply chain management and enterprise resource planning integration, International Journal of Physical Distribution $\mathcal{E}$ Logistics Management, 36 (6), pp. 455-465.

Kwon, T.H., and Zmud, R.W. (1987). Unifying the Fragmented Models of Information Systems Implementation, in: Critical Issues in Information Systems Research R.J. Boland, Jr. and R.A. Hirschem (Eds.), Wiley, New York.
Lee H \& Whang S (2001). E-business and Supply Chain Integration. Stanford Global Supply Chain Management Forum, SGSCMF-W2-2001, November.

Lee H (2004). The Triple A Supply Chain. Harvard Business Review 82(10), pp. 102-112.

Lee, H. L., \& Whang, S. (2000). Information sharing in a supply chain. International Journal of Technology Management, 20(3/4), pp. 373-387

Lee, H.L. (2003). Efficiency alone won't fix supply chain. EBN Manhasset, September 15, p. 4.

Lee, J. (2001). The impact of knowledge sharing, organizational capability and partnership quality on IS outsourcing success. Information $\mathcal{E}$ Management, 38, pp. 323 - 335.

Lee, H.L., Padmanabhan V. and Whang, S. (1997) The paralysing curse of the bullwhip effect in a supply chain, Sloan Management Review, Spring pp93-102

Li, S., \& Lin, B. (2006). Accessing information sharing and information quality in supply chain management. Decision Support Systems, 42(3), pp.1641-1656

Li, S., Ragu-Nathan, B., Ragu-Nathan, T. S., \& Subba Rao, S. (2006). The impact of supply chain management practices on competitive advantage and organizational performance. Omega, 34(2), pp. 107-124

Li, X., Wang, Q. (2007). Coordination mechanisms of supply chain systems, European Journal of Operational Research, 179 (1), pp. 1-16.

Maloni M., Benton, W.C. (2000). Power influences in the supply chain, Journal of Business Supply chain, 21 (1), pp.4974.

Mason-Jones, R. and Towill, D.R., (1997). Information Enrichment: Designing the Supply Chain for Competitive Advantage, Supply Chain Management, 2 (4), pp 137-148.

Mentzer, J.T., DeWitt, W., Keebler, J.S., Min, S., Nix, N.W., Smith, C.D., Zacharia, Z.G. (2001). Defining supply chain management, Journal of Business Supply chain, 22 (2), pp.124.

Moakley, J.M., Young, M. (1997). The internet and the supply chain, Annual Conference Proceedings, Council of Supply chain Management, Oak Brook, IL, pp.153-61.

Moberg CR, Cutler BD, Gross A \& Speh TW (2002). Identifying antecedents of information exchange within supply chains. International Journal of Physical Distribution $\mathcal{E}$ Logistics Management 32(9), pp. 755-770.

Moberg, C. R., Cutler, B. D., Gross, A., \& Speh, T. W. (2002). Identifying antecendents of information exchange within supply chains. International Journal of Physical Distribution $\mathcal{E}$ Logistics Management, 32(9), pp. 755-770.

Moorman, D., Deshpande, R., Zaltman, G. (1993). Factors affecting trust in market research relationships, Journal of Marketing, 57 (1), pp.81-101.

Morgan, R.M., Hunt, S.D. (1994). The commitment-trust theory of relationship marketing, Journal of Marketing, 58 (3), pp.20-38. 
Muzumdar, M., and B. Narayan (2001). Supply Chain Evolution: Role, Responsibilities and Implication for Management, and the Performance Advantage, APICS, 11 (10), pp.57-61.

Naumann, F. \& Rolker, C. (2000). Assessment methods for information quality criteria. Proceedings of $5^{\text {th }}$ International Conference on Information Quality, pp.148-162

Patnayakuni, R., Rai, A., Seth, N. (2006). Relational antecedents of information flow integration for supply chain coordination, Journal of Management Informational Systems, 23 (1), pp. 13-49.

Perry, J. (1991). Emerging Economic and Technological Futures: Implications for Design and Management of Logistics Systems in the 1990s. Journal of Business Logistics, 12 (2), pp. 1 -16.

Petersen, K.J., Ragatz, G.L., Monczka, R.M. (2005). An examination of collaborative planning effectiveness and supply chain performance, The Journal of Supply Chain Management, 41 (2), pp. 14-25.

Rogers, D.S., Daugherty, P.J., Ellinger, A.E. (1996). The relationship between information technology and warehousing performance, The Supply Chain and Transportation Review, 32 (4), pp.409-21.

Sanders, N \& Premus, R 2005, 'Modeling the relationship between firm IT capability, collaboration and performance', Journal of Business Logistics, vol. 26, no. 1, pp. 1-23.

Sawhney, R. (2006). Interplay between uncertainty and flexibility across the value chain: Towards a transformation model of manufacturing flexibility, Journal of Operations Management, 24 (5), pp. 476-493.

Seidmann, A. and Sundararajan, A. (1998). Sharing Logistics Information Across Organizations: Technology, Competition, and Contracting, in Information Technology and Industrial Competitiveness, C. Kemerer (Ed.), Kluwer Academic Publishers.

Sekaran, U. (2003). Research Methods for Business Approach. $4^{\text {th }}$ edition. Singapore: John Wiley \& Sons Inc.

Simatupang, M. T. and Sridharan, M. R. (2005). “The collaboration index: A measure for supply chain collaboration," International Journal of Physical Distribution $\mathcal{E}$ Logistics Management, Vol. 35, No. 1, pp. 44
Simchi-Levi \& Kaminsky, K. (2000). Designing and Managing the Supply Chain. New York: McGraw-Hill Company.

Skjoett-Larsen, T. (2000). Third Party Logistics - From an Interorganizational Point of View, International Journal of Physical Distribution $\mathcal{E}$ Logistics Management, 30 (2), pp. 112 - 117.

Stank, T.P., Daugherty, P.J., Ellinger, A.E. (1996). Information sharing, responsiveness, and supply chain provider performance, The International Journal of Supply chain Management, 7 (2), pp.43-57.

Stank, T.P., Emmelhainz, M.A., Daugherty, P.J. (1996). The impact of information on supplier performance, Journal of Marketing Theory and Practice, 4 (4), pp.95-105.

Stevenson, M., Spring, M., (2007). Flexibility from a supply chain perspective: definition and review, International Journal of Operations \& Production Management, 27 (7), pp. 685-713.

Tornatzky, L. G., Fleischer, M. (1990). The Processes of Technological Innovation, Lexington Books

Walton, L.W., Miller, L.G. (1995). Moving toward LIS theory development: a framework of technology adoption within channels, Journal of Business Supply chain, 16 (2), pp.11733.

Whipple, J.M. \& Frankel, R. (2000). Strategic alliance success factors. Journal of Supply Chain Management, 36 (3), pp. 21-28.

Yong, A. (2002). Global supply chain management system connects manufacturers. Asia Pacific Information and Communication Technology, March/April. 15 (3): pp 500513.

Yu, Z., Yan, H. and Cheng, T.C.E. (2000). Benefits of Information Sharing with Supply Chain Partnerships, Industrial Management and Data Systems, 101 (3), pp 114119.

Zailani, S., \& Rajagopal, P., (2006). The Effects Of Information Quality On Supply Chain Performance: New Evidence From Malaysia. ISWORLD: Information Quality Managenent: Practice and Applications. published by Idea Group Publishing.

Dr. Suhaiza Zailani is an Associate Professor of Operations Management in the School of Management, Universiti Sains Malaysia. She has been teaching for the past 10 years as well as being involved in a few management consultancies focusing on the areas of operations management. She has more than 150 Research Publications in International/ National Seminars and Journals. She is quite comfortable in operations project related. Her areas of interest are supply chain, logistics, and transportations by involving in few important projects, which describe her capability. 
Dr. Premkumar is an Associate Professor of Supply Chain in the AIMST University, Malaysia. His research interest is in Supply Chain Management, Manufacturing, Logistics \& Warehouse Management and Services, Strategic Forecasting, Planning, Outsourcing, Cost Control \& Analysis and general operations management.

Yudi Fernando is a Fellow and PhD candidate from School of Management, Universiti Sains Malaysia. He has a MBA from School of Management, Universiti Sains Malaysia, Penang, Malaysia. His first degree is in Management from Universitas Andalas, Indonesia. His current research interest is in Service Marketing, Marketing Management, Industrial Marketing, and Supply Chain Relationship and Logistic area. 